\title{
PERSPECTIVAS DA SUBJETIVAÇÃO DA RACIONALIDADE NEOLIBERAL
}

Rafael Xavier Tolentino

\section{Resumo}

O presente trabalho trata-se de estudo exploratório que objetiva uma análise panorâmica dos aspectos históricos, sociais, políticos e éticos envolvidos com a racionalidade neoliberal, bem como seus impactos na subjetividade. Adotou-se como método a pesquisa bibliográfica, cujo percurso metodológico iniciou-se com a análise da obra de Dardot e Laval (2016), adotada como base estrutural a partir da qual são estabelecidos diálogos com os conceitos encontrados em Nunes (2017a e 2017b), Milanovic (2017a e 2017b), Damásio (2011) e Jonas (1995). A linha de fundo subjacente ao artigo compreende a visão da sociedade como uma instituição dotada de uma forma construída histórica e socialmente, na qual incidem forças internas e externas continuamente empenhadas em modificar (reformar) seu conteúdo, cujo equilíbrio determina a continuidade de sua existência ou a possibilidade de se deformar (ruptura social). Concluiu-se o trabalho com a exposição de alguns dos principais problemas relacionados à extrema capilaridade tomada pela racionalidade neoliberal nas mais diversas esferas da sociedade, bem como os direcionamentos apontados pelos autores ora referenciados rumo à construção de soluções.

Palavras-chave: Crise. Ética. Neoliberalismo. Ruptura Social. Subjetividade.

\section{DES PERSPECTIVES DE LA SUBJECTIVATION DE LA RATIONALITÉ NÉOLIBÉRALE}

\section{Résumé :}

Ce travail concerne une étude exploratoire avec l'objectif de faire une analyse panoramique des aspects historiques, sociaux, politiques et étiques qui sont en rapport avec la rationalité néolibérale. Également, nous soulignons ses effets sur la subjectivité. Nous avons adopté la méthode de recherche bibliographique, dont le parcours méthodologique commence par l'analyse de l'œuvre de Dardot et Laval (2016), qui est la base structurale sur laquelle sont établis les dialogues avec les concepts trouvés dans Nunes (2017a et 2017b), Milanovic (2017a et 2017b), Damásio (2011) et Jonas (1995). Cet article est basé sur la conception de la société comme une institution dont la forme est construite par l'histoire et la société, sous l'influence des forces internes et externes continuellement engagées dans la modification (réformation) de son contenu, dont l'équilibre détermine la continuité de son existence ou la possibilité de sa déformation (rupture sociale). Pour finir, nous exposons quelques problèmes liés à l'extrême capillarité de la rationalité néolibérale dans les diverses sphères de la société, ainsi que les directions données par les auteurs cités visant à la construction des solutions.

Mots-clés : Crise. Éthique. Néolibéralisme. Rupture sociale. Subjectivité.

CSOnline - Revista Eletrônica de Ciências Sociais, Juiz de Fora, n. 25 (2017), pp. 1-296. 


\section{Introdução}

A motivação do presente estudo exploratório surgiu da necessidade de composição de um quadro conjuntural a partir de múltiplas perspectivas, tarefa para qual se realizou pesquisa bibliográfica com fundações inspiradas na estrutura subjacente ao ensaio sobre a sociedade neoliberal elaborado por Dardot e Laval (2016), cuja impressão da primeira edição francesa se deu no início de 2009 - momento no qual ainda se avaliavam a profundidade dos impactos da crise de 2008. O percurso metodológico seguiu pela escolha das obras de Nunes (2017a e 2017b) e Milanovic (2017a e 2017b), visando estabelecer um diálogo entre os conceitos dos três autores em busca de seus pontos convergentes e divergentes. Em seguida, foram escolhidas as obras de Damásio (2011) e Jonas (1995) com propósito específico na expansão das concepções relacionadas às questões éticas e da subjetividade encontradas na obra de Dardot e Laval (2016). Finalmente, a partir da análise e integração das formulações encontradas, elaborou-se a síntese do quadro conceitual apresentado no presente artigo.

Dardot e Laval colocam em xeque, na referida obra, a ideia de que a crise de 2008 ocasionaria o enfraquecimento das políticas neoliberais, tratando-se na realidade, do brutal fortalecimento de uma ideologia que predomina na forma de um sistema normativo

(...) capaz de orientar internamente a prática efetiva dos governos, das empresas e, para além deles, de milhões de pessoas que não têm necessariamente consciência disso. O neoliberalismo define certa norma de vida (...) que impõe a cada um de nós que vivamos num universo de competição generalizada, intima os assalariados e as populações a entrar em luta econômica uns contra os outros, ordena as relações sociais segundo o modelo do mercado, obriga a justificar desigualdades cada vez mais profundas, muda até o indivíduo, que é instado a conceber a si mesmo e a comportar-se como uma empresa. Trata-se de uma nova razão do mundo, cujo sucesso normativo pode ser descrito como político, econômico, social e subjetivo, enfim, integra todas as dimensões da existência humana. (...) $\mathrm{O}$ neoliberalismo antes de ser uma ideologia ou uma política econômica, é em primeiro lugar e fundamentalmente uma racionalidade e, como tal, tende a estruturar e organizar não apenas a ação dos governantes, mas até a própria conduta dos governados. (DARDOT e LAVAL, 2016, p.15-16)

CSOnline - Revista Eletrônica de Ciências Sociais, Juiz de Fora, n. 25 (2017), pp. 1-296. 
Para os autores existe uma verdadeira batalha em torno dos interesses da alta administração, dos oligopólios, dos economistas e das mídias, cujo intuito é, além de promover modificações na economia, impor à sociedade o modelo da empresa e a lei (pouco natural) da concorrência, motivo que explica o esforço efetuado para enfraquecer as instituições e os direitos conquistados pelo movimento operário a partir do fim do século XIX. A gestão das economias e sociedades através desse modelo empresarial apresenta-se como um sistema de normas, que se inscreve nas práticas governamentais, nas políticas institucionais e nos estilos gerenciais, estendendo a lógica do mercado ao produzir uma subjetividade "contábil e financeira", através da criação de concorrência sistemática entre os indivíduos.

Assim, torna-se fulcral analisar os argumentos que normalmente são utilizados pela visão progressista, tal como a de Nunes (2017a), de modo a verificar se há, nesse sentido, certa incompletude na maneira como os fatos sociais e econômicos são percebidos. Faz-se útil também agregar a visão econômica de Milanovic (2017a e 2017b), cujo foco se dá na análise das desigualdades. Ademais, é igualmente premente verificar os desdobramentos éticos e mesmo psíquicos oriundos da adoção do referido modelo empresarial.

\section{Genealogia do neoliberalismo}

Para compor sua genealogia do neoliberalismo, Dardot e Laval (2016) iniciam pela descrição do "primeiro liberalismo", datado do século XVIII, que se destaca pela elaboração de limites ao governo, enquadrado por "leis" conjugadas que devem orientar, em termos utilitaristas, os interesses individuais de forma a fazê-los servir ao bem geral. A partir da metade do século XIX, o liberalismo apresenta fissuras oriundas da tensão entre duas vertentes internas que irão se aprofundar até a Primeira Guerra Mundial: a dos reformistas sociais, que defende um ideal de bem comum, e a dos partidários da liberdade individual como fim absoluto. Nesse momento, o surgimento da necessidade de intervenção governamental para lidar com as modificações enfrentadas pelo capitalismo - os conflitos de classe que ameaçam a "propriedade privada" e as novas relações de força internacionais - coloca o liberalismo em crise. O princípio dogmático do laissez-faire era incapaz de conduzir adequadamente os negócios CSOnline - Revista Eletrônica de Ciências Sociais, Juiz de Fora, n. 25 (2017), pp. 1-296. 
governamentais para atingir o objetivo declarado de garantir a maior prosperidade possível concomitantemente com a ordem social. Entre os que permanecem apegados aos ideais do liberalismo clássico, destacam-se dois tipos de respostas formuladas para lidar com os riscos impostos pelo totalitarismo (que significa a destruição da sociedade liberal).

\begin{abstract}
O "novo liberalismo", do qual uma das expressões tardias e mais elaboradas no plano da teoria econômica foi a de Keynes, consistiu em reexaminar o conjunto dos meios jurídicos, morais, políticos, econômicos e sociais que permitiam a realização de uma "sociedade de liberdade individual", em proveito de todos. (...) a realização dos ideais do liberalismo exige que se saiba utilizar meios aparentemente alheios ou opostos aos princípios liberais para defender sua implementação: leis de proteção do trabalho, impostos progressivos sobre a renda, auxílios sociais obrigatórios, despesas orçamentárias ativas, nacionalizações. Mas, se esse reformismo aceita restringir os interesses individuais para proteger o interesse coletivo, ele o faz apenas para garantir as condições reais de realização dos fins individuais. (DARDOT e LAVAL, 2016, p.69)
\end{abstract}

O outro tipo de resposta criado posteriormente foi o neoliberalismo, para o qual, conforme os autores, a intervenção do Estado trata-se não de limitar o mercado através de uma ação direta do Estado, mas de desenvolver e purificar o mercado concorrencial através de um enquadramento jurídico cuidadosamente ajustado. Combinando, desta forma, a reabilitação da intervenção pública com uma concepção do mercado centrada na concorrência. Nascido em 1930, significou uma ruptura em relação àquela versão dogmática do liberalismo. Em um contexto de crise econômica, política e doutrinal se operou uma refundação "neoliberal" da doutrina que se apresentou em duas vertentes divergentes: a corrente do ordoliberalismo alemão e a corrente austroamericana. Tratou-se de uma resposta ao reformismo social cada vez mais pronunciado a partir do fim do século XIX, ou seja, uma tentativa de travar essa orientação às políticas redistributivas, assistenciais, reguladoras e protecionistas, que eram vistas como uma degradação que conduziria diretamente ao coletivismo.

Neste ponto, cabe suspender, por um momento, a narrativa histórica de Dardot e Laval (2016) para introduzir as considerações de Nunes (2017a) sobre o que diz ser, atualmente, uma crise estrutural do capitalismo. Sua retrospectiva histórica define a abrangência desta em torno dos planos financeiro, econômico, social e também da democracia, cuja origem remonta à crise do petróleo na década de 70, momento em que se fortaleceu o fenômeno da tendência para a baixa da taxa média de lucro e se CSOnline - Revista Eletrônica de Ciências Sociais, Juiz de Fora, n. 25 (2017), pp. 1-296. 
evidenciou a financeirização da economia. Seus efeitos se deram, segundo o autor, no sentido da hegemonia do capital financeiro em relação ao capital produtivo, o que propiciou, em resposta, uma "revolução conservadora", iniciada com Thatcher e Reagan (ao final da década), momento a partir do qual o neoliberalismo se firmou como ideologia dominante (e das classes dominantes) sob a liderança do capital financeiro. A partir de então a ideologia tem recebido, em certa medida, um caráter dogmático, cujos adeptos têm defendido sua "fé" utilizando-se do inaceitável argumento thatcheriano de que "não há alternativa".

Após o desmoronamento da União Soviética, abriu-se o caminho ao reino do deus-mercado, à sobre-exploração dos trabalhadores, assumindo sem disfarce os genes do capitalismo como a civilização das desigualdades. (...) O neoliberalismo corresponde a uma nova fase na evolução do capitalismo, convencido de que pode permitir ao capital todas as liberdades, incluindo as que matam as liberdades dos que vivem do rendimento do seu trabalho. (...) [Trata-se de uma] ditadura do grande capital financeiro. (NUNES, 2017a)

De acordo com este autor, após a ocorrência da crise de 2008, até a mídia conservadora foi forçada a aceitar que a desigualdade chegou a um patamar que a torna ineficiente e nefasta para o crescimento. As ameaças à democracia e a possibilidade de testemunharmos um fim do estado social podem ser notadas como um sinal de que, como o aprendiz de feiticeiro, o capitalismo pode morrer imolado pelo fogo que está a atear.

(...) [A atual crise] não será a última, mas ela ajudará a enfraquecer ainda mais este corpo condenado a morrer (como tudo o que é histórico) e a dar lugar a um mundo diferente, apesar de todos os meios - e são muitos - que podem ainda prolongar-lhe a vida. (NUNES, 2017a)

Embora plenamente em consonância com a perspectiva de Dardot e Laval (2016) na maior parte de sua narrativa, surge nesses dois últimos tópicos de Nunes (2017a) um importante ponto divergente: a tese do enfraquecimento e da probabilidade de morte do capitalismo. Para aqueles autores, a crise opera, pelo contrário, no sentido de fortalecimento do neoliberalismo, posto ser este muito mais do que uma doutrina (conforme descrito anteriormente, aquela elaborada em 1930) e sim uma racionalidade governamental - de "efeito global" - desenvolvida nos anos 1980-1990 resultado de múltiplos processos heterogêneos.

CSOnline - Revista Eletrônica de Ciências Sociais, Juiz de Fora, n. 25 (2017), pp. 1-296. 
Em certo alinhamento com Dardot e Laval (2016), nesse quesito, Milanovic (2017b) assinala em sua ótica da história econômica, referente à segunda metade do século $\mathrm{XX}$, que a democracia capitalista liberal lutou contra todos os desafiadores e sobreviveu, não porque todos viram que era um sistema mais "natural", como a narrativa triunfalista o considera, mas porque usava o poder e a intimidação, por um lado, e um desempenho econômico superior para as massas no outro. Sendo, assim, necessário perceber a crise atual como apenas uma das muitas crises do capitalismo.

Retoma-se a narrativa de Dardot e Laval (2016), segundo os quais aquelas duas correntes do neoliberalismo do início do século - novo liberalismo e neoliberalismo consideravam como inimigos comuns o coletivismo (comunista ou fascista) bem como as tendências políticas reformistas (como o keynesianismo), importando a eles, nesse momento, o combate conjunto contra o "intervencionismo de Estado" e a "escalada do coletivismo". O que o neoliberalismo apresenta de novo é sua ênfase na relação entre as instituições e a ação individual. A partir do momento que se observa a conduta econômica maximizadora como algo não natural, faz-se necessário, então, explicitar quais fatores a influenciam em direção à eficácia.

\begin{abstract}
As diferenças entre os autores neoliberais estão ligadas, em parte, à solução que eles dão a esse problema. Enquanto os principais responsáveis pelo "renascimento neoliberal" - Rougier, Lippman e os ordoliberais alemães destacam a necessidade da intervenção governamental, os autores austroamericanos (...) [Ludwig von Mises e Friedrich Hayek, dão ênfase à ação individual e ao processo de mercado. Esses últimos] visam, em primeiro lugar, a produzir uma descrição realista de uma máquina econômica que tende ao equilíbrio, quando não é perturbada por moralismos ou intervenções políticas e sociais destruidoras. Em segundo lugar, visam a mostrar como se constrói na concorrência geral certa dimensão do homem, o enterpreneurship, que é o princípio de conduta potencialmente universal mais essencial à ordem capitalista. (...) É precisamente essa dimensão antropológica do homem-empresa que, de um modo diferente daquele da sociedade ordoliberal, será a principal contribuição dessa concorrente. (DARDOT e LAVAL, 2016, p.134)
\end{abstract}

A doutrina austríaca privilegia as dimensões da competição e da rivalidade, consubstanciadas em uma teoria da ação humana na qual a vida econômica é descrita a partir da luta dos agentes, empreendedores, movidos por um espírito empresarial que só é "limitado" pelo Estado - através da liberação ou refreamento à livre competição. "Foi particularmente no campo do management que essa orientação encontrou sua expressão mais forte". (DARDOT e LAVAL, 2016, p.136) Para essa corrente a questão primordial 
é descobrir como legitimar um determinado tipo de intervenção governamental, sem admitir, como os ordoliberais, que a ordem (artificial) de mercado é quem cria a coesão da sociedade.

Nos anos 1980, os autores identificam Ronald Reagan e Margaret Thatcher como símbolos do rompimento com as políticas de bem estar da socialdemocracia. Seu principal atributo é a forma radicalmente diferente de exercício do poder, através de uma política conservadora e neoliberal, em um contexto de financeirização e globalização do capitalismo, correlatos a uma determinada racionalidade política e social. Relacionava a socialdemocracia ao intervencionismo do Estado e, por outro lado, o neoliberalismo com o livre mercado. Referenciado como "a grande virada", o período se caracterizou pelo esforço em busca da privatização e do desmantelamento do Estado social, o que caracteriza a existência de uma "estratégia neoliberal", embora não na forma de um complô, mas sim como um engajamento gradativo de grupos heterogêneos com objetivos em comum.

O neoliberalismo, quando inspira políticas concretas, nega-se como ideologia, porque ele é a própria razão.

Assim, políticas muito semelhantes podem moldar-se nas mais diversas retóricas (conservadoras, tradicionalistas, modernistas, republicanas, conforme a situação e o caso), manifestando desse modo sua extrema plasticidade. Dito de outra maneira, a dogmática neoliberal apresenta-se como uma pragmática geral, indiferente às origens partidárias. A modernidade ou a eficácia não são de direita nem de esquerda, segundo dizem os que "não fazem política". O essencial é que "funciona", como dizia com frequência Tony Blair. É isso também que nos permite avaliar as diferenças entre o período militante do neoliberalismo político de Thatcher e Reagan e o período gestionário, no qual se trata apenas de "boa governança", "boas práticas" e "adaptação à globalização". (...) Em resumo, a grande vitória ideológica do neoliberalismo consistiu em "desideologizar" as políticas seguidas, a ponto de não serem sequer objeto de debate. (DARDOT e LAVAL, 2016, p. 242)

\section{A ação pública impregnada pela lógica do neoliberalismo}

Para Dardot e Laval (2016), ao continuar a acreditar na possibilidade prática de uma autonomia dos interesses privados em relação ao Estado, os críticos do liberalismo incorrem no erro de considerar o mercado um dado natural, anterior à política, dando força à ideia de um desengajamento do Estado e liberando a ação do campo privado (livre mercado).

CSOnline - Revista Eletrônica de Ciências Sociais, Juiz de Fora, n. 25 (2017), pp. 1-296. 


\begin{abstract}
A principal crítica que se faz ao Estado é sua falta global de eficácia e produtividade no âmbito das novas exigências impostas pela globalização. (...) Esse é o objetivo da linha do "Estado eficaz", ou do "Estado gerencial", tal como este começa a se construir a partir dos anos 1980. (...) A diferença que essas políticas querem introduzir reside na eficiência dessa gestão e, por conseguinte, no método que se deve empregar para fornecer bens e serviços à população. Quando essa gestão fica nas mãos da administração pública, ela contraria - segundo as "evidências" da nova ortodoxia - a lógica de mercado quanto ao papel dos preços e à pressão da concorrência. Esse é o fundamento da posição antiburocrática da fração "modernista" dos dirigentes da administração do Estado e de seus especialistas. (DARDOT e LAVAL, 2016, p. 273)
\end{abstract}

Porém, advertem os autores, a lógica da competição mundial alterou a própria concepção da ação pública, de modo que o Estado tenha que administrar a sociedade e deixá-la à serviço do mercado ao mesmo tempo que tenha que se dobrar às regras de eficácia próprias das empresas privadas. O paradigma do management imposto às práticas de governo tem como objetivo aumentar a eficácia da ação pública, subvertendo os fundamentos da democracia ao tratar a intervenção política como uma interação horizontal entre atores privados, devendo, o Estado, ser submetido a um modo de controle extremamente rigoroso. A instituição do modelo de concorrência como o instrumento mais eficiente para aperfeiçoar a ação pública se dá pelo conceito gerencial da "boa governança", no campo das "boas práticas" econômicas, substituindo a ideia de soberania, vista como antiquada e desvalorizada.

A nova gestão pública, formada pela simbiose entre os meios empresariais privados e a alta administração, busca sua legitimidade na interseção entre "modernidade" e "ciência" e tem como objetivo o controle estrito dos agentes públicos, com foco nos resultados, que são contabilizados como na empresa privada. O objetivo é "fazer o indivíduo interiorizar as normas de desempenho e às vezes, mais do que isso, fazer com que o avaliado seja o produtor das normas de servidão para julgá-lo." (DARDOT e LAVAL, 2016, 314)

De acordo com os autores, o management se baseia na ilusão de considerar a interpretação puramente numérica dos resultados como uma representação completa da realidade, desprezando as dimensões não quantificáveis do ofício. Tal visão impacta na qualidade do serviço, posto considerar a dedicação e a consciência profissional como algo fictício. Através de modos de controle mais refinados, o serviço público perde seu significado próprio, uma vez que suas missões se veem embaralhadas com os valores de CSOnline - Revista Eletrônica de Ciências Sociais, Juiz de Fora, n. 25 (2017), pp. 1-296. 
uma produção do setor privado. Além de atuar como poderoso mecanismo de padronização e normalização de comportamentos, essa lógica contábil tende a desfazer as relações políticas entre o Estado e os cidadãos.

\begin{abstract}
A desconfiança como princípio e a vigilância avaliativa como método são os traços mais característicos da nova arte de governar os homens. O espírito gerencial que a anima impõe-se em detrimento dos valores hoje desqualificados do serviço público e da dedicação dos agentes a uma causa geral que está acima deles.(...) A partir do momento que o postulado da nova gestão especifica que não se pode mais confiar no "indivíduo comum", intrinsecamente privado de qualquer apego a um "espírito" público e de qualquer adesão a valores que lhe seriam exteriores, a única solução é o controle e o "governo à distância" dos interesses particulares. Quer se trate de equipe hospitalar, juízes ou bombeiros, os motivos e os princípios de sua atividade profissional são concebidos apenas do ângulo dos interesses pessoais e corporativos, negando-se, assim, qualquer dimensão moral e política de seu compromisso com uma profissão que repousa sobre valores próprios. A desconfiança caracteriza ainda a relação entre as instituições públicas e os sujeitos sociais e políticos, que também são vistos como "oportunistas" em busca da máxima vantagem pessoal, sem nenhuma consideração pelo interesse coletivo. (DARDOT e LAVAL, 2016, p. 320)
\end{abstract}

\title{
4. O neoliberalismo entranhado na subjetividade
}

A reestruturação neoliberal altera a definição de sujeito político, à medida que torna os cidadãos meros consumidores de serviços, que os julgam em termos de relações de custo-benefício. A expansão da mercantilização para o âmbito das relações humanas se deu através da contratualização destas, de modo que a sociedade seja percebida como um conjunto de relações de associação entre os indivíduos. Essa constatação de Dardot e Laval (2016) a respeito dos novos tempos serve de atualização à imagem delineada por Nunes (2017b) a respeito do contratualismo do antigo pensamento liberal (fundado por Adam Smith), que tem suas bases na diferenciação entre o contrato de trabalho, e os demais tipos de contrato. Sendo que aquele é firmado entre pessoas que não estão em posição de igualdade (trabalhadores versus proprietários), e no qual "uma das partes (os trabalhadores) não são, verdadeiramente, livres para contratar ou não contratar: juridicamente não estão obrigadas a trabalhar, mas, economicamente, são obrigados a vender sua força de trabalho". Dardot e Laval (2016) expandem o conceito, demonstrando que as relações contratuais se dão agora de forma global, em todas as esferas, uma vez que tanto o indivíduo é considerado uma empresa de si, quanto o próprio Estado assim o é, e, por isso, estão sujeitos a relações 
contratuais e às regras concorrenciais do mercado. Para os autores, o neoliberalismo político impactou efetivamente nas condutas dos indivíduos, uma vez que sua proposta é que cada um deve "cuidar de si mesmo", em oposição à ideia de solidariedade coletiva, maximizando seus interesses em um contexto de forte concorrência entre eles.

(...) cada uma a sua maneira, psicanálise e sociologia registram uma mutação do discurso sobre o homem que pode ser reportado, como em Lacan, à ciência de um lado e o capitalismo de outro.(...) Se existe um novo sujeito, ele deve ser distinguido nas práticas discursivas e institucionais que, no fim do século XX, engendraram a figura do homem-empresa ou do "sujeito empresarial", favorecendo a instauração de uma rede de sanções, estímulos e comprometimentos que tem o efeito de produzir funcionamentos psíquicos de um novo tipo. (...) $\mathrm{O}$ homem benthamiano era o homem calculador do mercado e o homem produtivo das organizações industriais. $\mathrm{O}$ homem neoliberal é o homem competitivo, inteiramente imerso na competição mundial. (DARTOT e LAVAL, 2016, p. 322)

As figuras de um sujeito produtivo e de um poder definido como essencialmente produtivo são características da sociedade industrial, conforme lembram os autores. Já na nova economia do homem, seu governo se dá pelos prazeres e pelas dores e através de uma política que glorifica a vigilância de todos sobre todos. Para a fabricação desse novo sujeito empresarial, substituem-se as antigas metodologias institucionais de coerção que visavam docilizar os espíritos por novas técnicas de gestão do novo sujeito que o façam trabalhar para a empresa como se trabalhasse para si mesmo, e assim eliminar o distanciamento entre o indivíduo e a empresa que o emprega. O novo governo dos sujeitos impõe ao sujeito um trabalho interior constante, que deve agir com a forma de um empreendedor de si mesmo, de modo que a economia seja transformada em disciplina pessoal, na gestão de si mesmo, que é avaliada através de seu comprometimento subjetivo com o trabalho.

Através de uma racionalização do sujeito, Dardot e Laval (2016) trazem um viés foucaultiano (o governo de si e dos outros) ao definir o conceito da empresa de si mesmo, tratada como um modelo que exige do indivíduo que procure maximizar seu capital humano de forma continua, objetivando a eficácia. Tal modelo define os paradigmas que regem o mercado de trabalho e o setor educacional, em termos de estratégias de melhoria contínua, empregabilidade e formação continuada.

O grande princípio dessa nova ética do trabalho é a ideia de que a conjunção entre as aspirações individuais e os objetivos de excelência da empresa ,entre o projeto pessoal e o projeto da empresa, somente é possível se cada indivíduo se tornar uma pequena empresa. Em outras palavras, isso pressupõe

CSOnline - Revista Eletrônica de Ciências Sociais, Juiz de Fora, n. 25 (2017), pp. 1-296. 
conceber a empresa como uma entidade composta de pequenas empresas de si mesmo. (DARDOT e LAVAL, 2016, p. 333)

Nesta questão, faz-se útil adotar uma perspectiva focada na interioridade dos processos mentais, tal como as investigações de Damásio (2011) a respeito do processo de construção da mente consciente no cérebro humano. $\mathrm{O}$ enfoque do autor se dá no desenvolvimento histórico da mente humana, porém, sem o desvincular dos aspectos sociais e culturais circundantes aos sujeitos. Segundo ele, é possível identificar um processo contínuo de evolução das camadas superiores do self através de modificações propiciadas pelos variados tipos de interações sociais e culturais às quais está submetido. Cabendo à consciência a responsabilidade de administrar e preservar a vida de modo eficiente (valor biológico), atividade à qual se dá o nome de homeostase. $\mathrm{O}$ autor ressalta o impacto proporcionado na consciência pelas sociedades globalizadas, bem como pela revolução digital, que estão ainda sendo avaliados. Ademais, em um importante alerta, relata sobre a existência de evidências científicas de que ao longo de muitas gerações, transformações culturais levam a mudanças efetivas no genoma.

(...) [A mente consciente dos humanos] apoiada por capacidades ainda maiores de memória, raciocínio e linguagem (...) abre caminho para modos de homeostase nas esferas da sociedade e da cultura. (...) Os sistemas judiciais, as organizações econômicas e políticas, a arte, a medicina e a tecnologia são exemplos dos novos mecanismos de regulação. A impressionante redução da violência e o aumento da tolerância que se evidenciam sobremaneira em séculos recentes não teriam ocorrido sem a homeostase sociocultural. E o mesmo se pode dizer da transição gradual do poder coercitivo para o poder de persuasão que caracteriza os sistemas sociais e políticos avançados, não obstante suas falhas.

(DAMÁSIO, 2011, p. 40-41)

Segundo Dardot e Laval, é necessário que seja analisada a relação entre as condutas dos neossujeitos e as formas de controle exercidas sobre eles por meio dos instrumentos da gestão social na qual se articulam os campos da medicina e da psicologia.

\footnotetext{
A espécie de desacoplamento verificado pelo diagnóstico clínico dos neossujeitos - o estado de suspensão fora dos quadros simbólicos, a relação flutuante com o tempo, as relações com os outros reduzidas a transações pontuais - não é disfuncional com relação aos imperativos do desempenho ou às novas tecnologias de rede. (DARDOT e LAVAL, 2016, p. 373)
}

CSOnline - Revista Eletrônica de Ciências Sociais, Juiz de Fora, n. 25 (2017), pp. 1-296. 


\title{
5. Ética e neoliberalismo
}

Conforme Dardot e Laval (2016), além dos limites da empresa, a ética neoliberal se expande por todos os domínios da existência propondo que se trabalhe o eu de modo a aumentar a eficácia da relação com o outro. Para tal, existe uma profusão de técnicas (coaching, programação neurolinguística, análise transacional) que propõe uma transformação dos indivíduos visando adaptá-los melhor à realidade. Porém, o modelo parte do princípio que se o indivíduo é consciente e efetua suas escolhas livremente, deve ser responsável por tudo o que lhe acontece, e, desta forma, lança o peso da competitividade - e seus riscos - exclusivamente sobre ele. Assim, os problemas econômicos são tratados como problemas relacionados a uma falta de domínio de si mesmo e de sua relação com os outros.

\begin{abstract}
A distribuição dos recursos econômicos e das posições sociais é vista exclusivamente como consequência de percursos, bem sucedidos ou não, de realização pessoal. Em todas as esferas de sua existência, o sujeito empresarial é exposto a riscos vitais, dos quais ele não pode se esquivar, e a gestão desses riscos está ligada a decisões estritamente privadas. Ser empresa de si mesmo pressupõe viver inteiramente em risco. (...) Do mesmo modo e ao mesmo tempo que se produz o sujeito de risco, produz-se o sujeito da assistência privada. (DARDOT e LAVAL, 2016, p. 346)
\end{abstract}

Para os autores, se o modelo industrial é marcado pelo relacionamento entre uma ascese puritana do trabalho com a satisfação do consumo e a esperança do gozo dos bens acumulados, no modelo neoliberal, diferentemente, espera-se do novo sujeito que maximize indefinidamente tanto a produção quanto o gozo. A partir da mesma lógica, considera-se haver uma efetiva igualdade entre os indivíduos frente às novas obrigações, de forma que nenhuma deficiência de nascença ou de ambiente possa ser um empecilho para um obrigatório comprometimento com a maximização do desempenho pessoal. A partir da conjunção do discurso psicológico, com a norma da concorrência e da representação do indivíduo como "capital humano" criou-se um modelo de desempenho/gozo que define as formas de identidade entre o sujeito psicológico e o sujeito da produção. Tal modelo, propagandeado incessantemente por meio de um discurso publicitário do "sucesso" como valor supremo.

A psicanálise pode nos ajudar a refletir sobre a maneira como funcionam os neossujeitos de acordo com o regime do gozo de si. Segundo Lacan, esse gozo de si, entendido como aspiração à plenitude impossível - nesse sentido, muito diferente do simples prazer -, apresenta-se na ordem social como sempre limitado e parcial. A instituição é, de certo modo, aquilo que tem a responsabilidade de limitar o gozo e dar sentido a esse limite. A empresa, CSOnline - Revista Eletrônica de Ciências Sociais, Juiz de Fora, n. 25 (2017), pp. 1-296. 
forma geral da instituição humana nas sociedades capitalistas ocidentais, não foge a essa regra, salvo por fazer isso hoje de maneira denegada. Ela limita o gozo de si pela coerção do trabalho, da disciplina, da hierarquia, por todas as renúncias que fazem parte de certa ascese laboriosa. A perda de gozo não é menos pronunciada do que nas sociedades religiosas, mas é diferente. Os sacrifícios não são mais administrados e justificados por uma lei dada como inerente à condição humana, sob suas diferentes variedades locais e históricas, mas pela reivindicação de uma decisão individual "que não deve nada a ninguém”. (DARDOT e LAVAL, 2016, p. 371)

Diferentemente dos valores anteriores que exigiam a renúncia individual em proveito de uma força coletiva, os autores ressaltam que a nova lógica normativa faz com que o sujeito seja ao mesmo tempo o trabalhador a acumular capital e o acionista a desfrutar dele, o que, juntamente com a ideia do desempenho sem limites e do gozo sem obstáculos, compõe o imaginário do sujeito liberal.

Chegará o tempo em que a questão da responsabilidade humana, em termos morais gerais e nos assuntos da justiça e sua aplicação, levará em conta a ciência da consciência que hoje se desenvolve. (...) a compreensão da construção neural da mente consciente também adiciona uma dimensão útil à tarefa de investigar como se desenvolvem e se moldam as culturas, o supremo produto dos coletivos de mentes conscientes. (DAMÁSIO, 2011, p. 43)

Adicione-se a esse quadro a questão problematizada por Hans Jonas, em seus estudos sobre as questões éticas, motivados pela questão da bomba atômica na Segunda Guerra Mundial. Percebem-se em sua tese dois importantes pontos de interseção com Damásio (2011): na questão da homeostase sociocultural (termo empregado por Damásio) e no fato de elaborarem uma revisão do pensamento cartesiano. Jonas parte do metabolismo celular para explicar a questão da dualidade cartesiana, basilar às suas concepções filosóficas a respeito da ética. Damásio, parte da questão mente versus cérebro, para estudar a concepção e evolução da consciência, de onde deriva suas considerações sobre a ética, aspectos sociais e culturais associados às questões psíquicas.

O fenômeno da vida, segundo Jonas, seria capaz de juntar as duas partes separadas do ser da tradição cartesiana (...) entre objetividade e subjetividade, exterioridade e interioridade, materialismo e idealismo, pois não pode ser simplesmente reduzida à res extensa. No organismo, encontram-se elementos de liberdade, subjetividade e interioridade que desmentem o fato de que a natureza é algo totalmente alheio à res cogitans. (...) Numa atmosfera ameaçadora, os organismos, desde os mais simples aos mais complexos, procuram, desejam (mesmo que de forma inconsciente) conservar sua vida perante a iminência da morte. (...) Superar o dualismo cartesiano se tornava necessário para se falar de novo sobre um valor da natureza, capaz de superar a visão extrativista que se cultivou desde Descartes, levando o Ocidente à crise ecológica em que se encontra. A crise se tornou mais nefasta graças ao

CSOnline - Revista Eletrônica de Ciências Sociais, Juiz de Fora, n. 25 (2017), pp. 1-296. 
extremo poder sobre a natureza que se adquiriu com a tecnologia moderna. De fato, sem negar as grandes contribuições da ciência para o Ocidente, a aliança entre dualismo cartesiano, mecanicismo newtoniano, capitalismo extrativista e tecnologia moderna conduziu o planeta a uma condição insuportável que precisa ser regulada por uma nova ética que inclua o valor da natureza em seu raio de reflexão. Era preciso superar o erro que desencadeara todo o processo de supervalorização do sujeito em detrimento da natureza, a saber: o dualismo de substâncias de Descartes. (VIANA, 2016, pos. 464)

Faz-se necessário, ao conceber uma nova ética - tal como proposta por Jonas (1995) -, considerar uma concomitante investigação aprofundada sobre os mecanismos neurais - como a efetivada por Damásio (2011). O imperativo se revela a partir do momento que analisamos a tese desse autor que desconstrói a ideia de que o self seja sempre sensato e esteja sempre no controle de todas as decisões.

Chegará o tempo em que a questão da responsabilidade humana, em termos morais gerais e nos assuntos da justiça e sua aplicação, levará em conta a ciência da consciência que hoje se desenvolve. (...) a compreensão da construção neural da mente consciente também adiciona uma dimensão útil à tarefa de investigar como se desenvolvem e se moldam as culturas, o supremo produto dos coletivos de mentes conscientes. (DAMÁSIO, 2011, p. 43)

\section{A democracia ameaçada}

Dardot e Laval (2016) identificam que à medida que a racionalidade mercantil provoca uma cisão entre a esfera pública e a esfera privada, abalam-se os fundamentos da democracia liberal, o que se intensifica pela contestação de seus fundamentos culturais e morais. Com critérios próprios de legitimação, a nova racionalidade se distancia desses valores e trata as leis e normas como meros instrumentos para realização de seus objetivos gerenciais, o que reflete em um desencantamento generalizado pela política.

A tese do Estado forte leva os neoliberais a reconsiderar o que se entende por democracia e, mais particularmente, por "soberania do povo". O Estado forte somente pode ser governado por uma elite competente, cujas qualidades são o exato oposto da mentalidade mágica e impaciente das massas. (DARDOT e LAVAL, 2016, p.98)

Em uma análise da relação entre desigualdade e política, Milanovic (2017a) ressalta que em qualquer sistema político, o poder se concentra entre os mais ricos - o que vale, evidentemente, para a democracia. A situação se torna perigosa quando se começa a utilizar o poder político para solidificar de forma ainda mais intensa o poder econômico dos ricos. $\mathrm{O}$ autor destaca ainda a existência de uma forte relação entre o CSOnline - Revista Eletrônica de Ciências Sociais, Juiz de Fora, n. 25 (2017), pp. 1-296. 
aumento da desigualdade e o enfraquecimento da democracia, o que pode se transformar, em um caso mais extremo, no estabelecimento de uma plutocracia.

O fundamental é compreender que nada pode nos eximir da tarefa de promover outra racionalidade. É por isso que a crença de que a crise financeira anuncia por si só o fim do capitalismo neoliberal é a pior das crenças. (...) No fundo, é a forma menos aceitável de renúncia intelectual e política. O capitalismo neoliberal não cairá como uma "fruta madura" por suas contradições internas, e os traders não serão a contragosto os “coveiros" inopinados desse capitalismo. (...) Cabe a nós permitir que um novo sentido do possível abra caminho. O governo dos homens pode alinharse a outros horizontes, além daqueles da maximização do desempenho, da produção ilimitada, do controle generalizado. Ele pode sustentar-se num governo de si mesmo que leva a outras relações com os outros, além daquelas da concorrência entre "atores empreendedores". As práticas de "comunização" do saber, de assistência mútua, de trabalho cooperativo podem indicar traços de outra razão do mundo. Não saberíamos designar melhor essa razão alternativa senão pela razão do comum. (DARDOT e LAVAL, 2016, p. 402)

\section{Considerações finais}

A respeito da realidade brasileira atual, ressalta-se que, historicamente, as crises aqui se desdobram de modo peculiar com impactos muito profundos, dada as características próprias da conformação social brasileira. Enquanto a narrativa hegemônica é centrada em um debate de direita versus esquerda, causador de um clima de ódio político e social intensificado pela mídia de massa, as reais disputas de poder ocorrem em uma camada mais profunda, nas quais se instrumentalizam sem resistência as forças agregadas pelo mercado, cujo propósito primordial é eliminar a velha política - que atuava até então como fator intermediário. Embora tal crise tenha muitos de seus sintomas explícitos, como se nota no campo político, o fato de tratar-se de uma racionalidade entranhada no seio das relações sociais e mesmo no interior do indivíduo torna sua investigação uma tarefa intensamente desafiadora.

De forma sintética, o argumento de Dardot e Laval (2016) traz a extensão da lógica do mercado a todas as esferas da existência humana, tratando-se de, mais do que uma ideologia, um projeto social e político, cuja pauta é definir a forma como os indivíduos são levados a se comportar, a se relacionar com os outros e consigo mesmos. Resulta-se em uma subjetivação do estabelecimento da concorrência em todos os níveis que se alavanca em fenômenos do desemprego, precariedade, dívida, avaliação e das formas de gestão na empresa.

CSOnline - Revista Eletrônica de Ciências Sociais, Juiz de Fora, n. 25 (2017), pp. 1-296. 
Delineia-se, assim, um cenário perturbador que sugere a premente necessidade de que sejam pesquisadas soluções, cujas diretrizes alguns dos autores ora elencados se dedicaram a sugerir. Para Nunes (2017a) é necessário perceber a globalização neoliberal como um verdadeiro projeto político, criado e executado de forma consciente pelos grandes "senhores do mundo" e apoiado por uma espécie de totalitarismo do pensamento único. Seus adversários precisam trabalhar para evitar uma nova era de barbárie, executando um projeto político alternativo, alicerçado sobre a confiança no homem e em suas capacidades, e inspirado em valores direcionados a objetivos distintos daqueles colocados pelo mercado.

Para sairmos desta caminhada vertiginosa para o abismo, é necessário evitar que o mercado substitua a política, que as "leis do mercado" se sobreponham aos normativos constitucionais e que o estado democrático ceda o lugar a um qualquer estado tecnocrático. (NUNES, 2017a)

Assim como Nunes (2017a); Milanovic (2017b), Dardot e Laval (2017) não consideram a neoliberalização acelerada das sociedades como um destino fatal. Os dois últimos, em específico, consideram que as causas da crise estrutural vigente se baseiam na desproporção de forças entre uma lógica dominante e uma lógica minoritária, de forma que a primeira se alimenta de "fenômenos mórbidos", como as crises e o ódio social.

\begin{abstract}
Por outro lado, a lógica minoritária do comum ainda não encontrou sua expressão de massas, seus marcos institucionais ou gramática política. Estamos apenas no início de uma nova configuração revolucionária. E esse atraso nos perturba. (...) Se trata aqui de ter em conta a radicalização neoliberal em toda a diversidade e complexidade de seus aspectos . É entender de que modo a crise multiforme que estamos vivendo, longe de ser um freio, tornou-se um meio para governar. O neoliberalismo não para, diante os efeitos da insegurança e destruição que ele próprio engendra, de se autoalimentar e autoreforçar. (DARDOT e LAVAL, 2017, pos 135. tradução nossa)
\end{abstract}

Ao lançar novamente o olhar sobre os pressupostos estabelecidos em Dardot e Laval (2016), partindo agora de uma lente focada na intimidade dos processos mentais do indivíduo em relação aos aspectos sociais e culturais aos quais está circunscrito, encontra-se uma temática que justifica um estudo mais aprofundado. Pode-se conjecturar, de início, sobre a possibilidade de que o mecanismo da homeostase sociocultural atue como um processo de segurança que garante, em certa medida, a coesão (forma) da sociedade, posto operar em um regime diferenciado. Juntem-se, neste 
cenário, as constatações foucaultianas de Dardot e Laval (2016) a respeito da força do neoliberalismo se encontrar justamente na fusão entre o governo de si e o governo do outro, e torna-se nítida a gravidade das implicações dessa racionalidade global sobre esse processo de homeostase sociocultura. As perspectivas de deformidade do tecido social se tornam cada vez mais prováveis, motivo que torna imprescindível um delinear preciso deste complexo quadro antes de se pensar em quaisquer estratégias de intervenção, ou reforma. Para completar o horizonte, é importante sublinhar o alerta de Damásio (2011) sobre haver evidências de que transformações culturais reiteradas ocasionam mudanças efetivas no genoma, pois daí se depreende, em certa medida, uma materialização da lógica neoliberal, a qual, extrapolando o sistema de crenças dos indivíduos, se convergeria em uma inscrição corpórea.

\section{REFERENCIAS BIBLIOGRÁFICAS}

DAMÁSIO, António R. E o cérebro criou o Homem. Tradução Laura Teixeira Motta. São Paulo: Companhia das Letras, 2011.

DARDOT, Pierre; LAVAL, Christian. A nova razão do mundo: ensaio sobre a sociedade neoliberal. Traduzido por Mariana Echalar. São Paulo: Boitempo, 2016.

DARDOT, Pierre; LAVAL, Christian. La pesadilla que no se acaba nunca: el neoliberalismo contra la democracia. Traducción Alfonso Díez. Barcelona: Editorial Gedisa, 2017.

JONAS, H. El Principio de Responsabilidad: Ensayo de una ética para la civilización tecnológica. Traductor: JAVIER MARÍA FERNÁNDEZ RETENAGA. Barcelona : Herder, 1995.

MILANOVIC, Branko. The higher the inequality, the more likely we are to move away from democracy. Disponível em: <https://www.theguardian.com/inequality/ 2017/may/02/higher-inequality-move-away-from-democracy-branko-milanovic-bigdata?CMP=share_btn_tw>. Acesso em 12 jun. 2017a.

MILANOVIC, Branko. The hidden dangers of Fukuyama-like triumphalism. Disponível em: <http://glineq.blogspot.com.br/2017/05/the-hidden-dangers-offukuyama-like.html>. Acesso em 13 jun. 2017 b.

NUNES, António J. A. António José Avelãs Nunes: depoimento [mai. 2017]. Entrevistador: P. H. Amorim. Disponível em: <https://www.conversaafiada.com.br/ economia/o-capitalismo-e-um-corpo-condenado-a-morrer>. Acesso em: 12 jun. 2017a. CSOnline - Revista Eletrônica de Ciências Sociais, Juiz de Fora, n. 25 (2017), pp. 1-296. 
NUNES, António J. A. A revolução francesa: as origens do capitalismo - a ordem jurídica da burguesia. Belo Horizonte: Fórum, $2017 \mathrm{~b}$.

VIANA, Wellistony C. Hans Jonas e a filosofia da mente. Org. Wellistony C. Viana. São Paulo: Paulus, 2016.

CSOnline - Revista Eletrônica de Ciências Sociais, Juiz de Fora, n. 25 (2017), pp. 1-296. 